\title{
Cap removal by honey bees leads to higher pollen rewards from grapevine flowers
}

\author{
Katja Hogendoorn, Kay Anantanawat, Cassandra Collins \\ School of Agriculture, Food and Wine, The University of Adelaide, Adelaide, SA 5005, Australia
}

Received 1 July 2015 - Revised 30 October 2015 - Accepted 24 November 2015

\begin{abstract}
Pollen of wind-pollinated plants such as grapevine rapidly dries out and is blown away after the anthers dehisce. Therefore, from the point of view of a pollen-collecting bee, pollen from wind-pollinated flowers is best collected soon after it becomes exposed. In grapevine, pollen becomes available immediately after the calyptra is shed, a process also referred to as capfall. We show, for the first time, that honey bees foraging on grapevine actively remove the calyptra from flowers. Using manual cap removal, we estimate that cap removal increases the pollen yield by $70 \%$ compared to collecting pollen from flowers after capfall. The bees selectively foraged on inflorescences with high numbers of loose caps, thus further enhancing their pollen revenue. We discuss the possible benefits of cap removal by honey bees for the development of individual berries and grape bunches of certain varieties.
\end{abstract}

\section{Apis mellifera / Vitis vinifera / foraging behaviour / calyptra}

\section{INTRODUCTION}

Foraging animals often enhance their returns by responding to the patterns of rewards encountered (Charnov 1976). For example, bees use a range of cues including olfaction, vision, and probing to distinguish between rewarding and unrewarding flowers and are known to modify flower visitation according to signals related to the quantity of nectar available (Goulson 1999; Leonard et al. 2011). Such responsiveness is particularly important when the potential to acquire a valuable reward is constrained by time, for example due to intense competition or when the resources themselves are ephemeral.

Wind-pollinated plants present ephemeral sources of pollen for palynivorous insects. While wind pollination generally coincides with the

Corresponding author: K. Hogendoorn, katja.hogendoorn@adelaide.edu.au Manuscript Editor: Stan Schneider production of large amounts of pollen (Faegri and van der Pijl 1971), the pollen release is synchronous (Bolmgren et al. 2003), and after the flower opens, pollen loss is rapid as the drying pollen grains are removed by the wind. Therefore, it is expected that bees foraging for pollen from wind-pollinated flowers develop strategies to enhance rewards by preferentially visiting newly opened flowers. In this context, we studied the forging strategies of honey bees (Apis mellifera L.) on the inflorescences of grapevine (Vitis vinifera L.).

In grapevine, anthesis starts with abscission of the fused petals, or cap, leading to capfall, which occurs mainly in the morning hours, between 6 a.m. and 10 a.m. (Pratt 1971; Staudt and Kassemeyer 1984; Vasconcelos et al. 2009). The anthers dehisce before or very soon after capfall (Staudt 1999; Vasconcelos et al. 2009), after which the pollen grains dry and disperse by wind. Thus, it is expected that the amount of pollen per flower available decreases from the time capfall.

The progress of capfall within an inflorescence follows a sigmoidal curve in grapevine (Pratt 
1971). Thus, inflorescences that have around $50 \%$ open flowers have a relatively high rate of capfall and are therefore expected to have a higher amount of pollen available compared to inflorescences in other stages of cap release. Consequently, if honey bees base their visitation on reward availability, they should preferentially visit inflorescences that have lost about $50 \%$ of their caps, as in these inflorescences fresh pollen become available at the highest rate.

While observing foraging behaviour, we noticed calyptrae falling out of bunches that were visited by honey bees. In addition, the bees seemed to search for flowers with lose caps and actively remove these, sometimes using their mandibles to pull on a loose lip of the cap (pers. obs.). This suggested that the bees actively removed caps from grape flowers, a behaviour that has not been previously described in honey bees. Describing this behaviour may seem trivial, but cap removal could have both negative and positive consequences for grape development and health. For example, nearly all of the pollen that is taken out of the system by the bees will not contribute to pollination and could therefore be interpreted as a form of pollen theft (Hargreaves et al. 2009). On the other hand, movement by bees among wind-pollinated flowers can increase the distance travelled by pollen kernels and the distance over which flowers are pollinated (Mangla and Tandon 2011), which may be beneficial in some grape varieties (Free 1993). In addition, loose caps in bunches, and caps that remain stuck on flowers, provide opportunities for colonisation by pathogens (Nair et al. 1988). Furthermore, in some varieties, such as Pinot Noir, persistence of the calyptra can cause the development of malformed grapes and bunches (Friend et al. 2003; Heazlewood and Wilson 2004).

To elucidate whether the bees actually removed caps and to evaluate the significance of cap removal of grapevine flowers by honey bees for pollen yield, we combined behavioural observations and experimental approaches to investigate: (a) whether honey bee foraging on grapevine enhanced capfall, (b) whether the bees had a preference for bunches that have a high capfall rate and thus a high number of lose caps and (c) whether cap removal increased their pollen reward compared to searching for flowers that had just lost their caps.

\section{MATERIALS AND METHODS}

The trials were performed in two vineyards on the University of Adelaide Waite Campus (South Australia, -34 58', 138 37'): 'Coombe' and 'Alverstoke', in spring 2011 and 2013. Both vineyards are used for teaching and research and contain numerous varieties of grapevine. The honey bee density was high in the immediate area; a small bee stand (5-10 hives) was situated $150 \mathrm{~m} \mathrm{~W}$ of the Coombe vineyard, and the arboretum surrounding the vineyards has a density of 28 feral honey bee hives $/ \mathrm{km}^{2}$ (Hogendoorn \& Fung pers. obs.).

\subsection{Visitation by bees to inflorescences at different stages of capfall}

To assess whether the bees preferentially visited inflorescences with high frequencies of capfall, we quantified the frequency of visits by bees to inflorescences at three stages of capfall (around 20, 50 and $80 \%$ capfall) in a single row of flowering Grenache, on four mornings between 27 October and 2 November 2011, between $8 \mathrm{a} . \mathrm{m}$. and $11 \mathrm{a} . \mathrm{m}$. The frequency of visitation of the different categories by honey bees was assessed by walking at a pace of $1 \mathrm{~km} / \mathrm{h}$ along the row and assessing the flowering category of each inflorescence on which a honey bee was seen to land. These frequencies were then compared to expected frequencies, which were based on the relative abundance of inflorescences in the different categories. These relative abundances were assessed just prior to the observations of bee behaviour, by categorising the flowering stage of 12 randomly chosen inflorescences in each vine in the row of Grenache ( $n=40$ vines, 480 inflorescences). The data collected for each day were analysed using a chi-square test, and the overall significance was tested using Fisher's combined probability test.

\subsection{Behaviour of foraging bees and consequences for capfall}

Cap removal behaviour by honey bees from flowers was observed and quantified in two ways. First, in a matched-pairs comparison, capfall was assessed by holding a hand for $10 \mathrm{~s}$ under a inflorescence that had both capped and uncapped flowers, while no honey bee 
was seen foraging on the inflorescence. After this, the inflorescence was observed for a 3-min period. If, in the scope of these $3 \mathrm{~min}$ no honey bee landed to forage at the inflorescence, a different inflorescence was selected and the process was repeated. If a honey bee did land within the 3-min period, the same hand was again held under the inflorescence for $10 \mathrm{~s}$, to collect fallen caps. In this way, the number of caps that fell within $10 \mathrm{~s}$ before and during a honey bee visit was recorded for 30 open pollinated inflorescences. The data were analysed using a Wilcoxon's matched-pairs signed-ranks test.

To verify that the foraging activity of the bees resulted in cap removal from flowers, rather than in loose caps falling out of visited inflorescences, we performed exclusion and inclusion tests in purposely designed tunnel-shaped cages, made out of fly-screen $(8 \mathrm{~m}$ by $2 \mathrm{~m}$ wide and $2.6 \mathrm{~m}$ high). The cages were erected over two 8-m sections of grapevines in a single row of Merlot, Cabernet Sauvignon and Chardonnay before the onset of flowering (23 October 2011). On the same day, 22 randomly chosen inflorescences with fully capped flowers were tagged in each tent for later evaluation. The next day, a queen-right nucleus honey bee hive was placed in one of the two cages per varietal. The hives contained approximately 1000 workers, a frame of eclosing brood, a full frame of honey and an empty frame. The other cage served to exclude bees and other visitors. Towards the end of flowering, when virtually all caps had dried or fallen off (4 November 2011 for Chardonnay and Merlot, 8 November 2011 for Cabernet Sauvignon), the flowers with dried calyptras attached were counted on tagged inflorescences in all six cages. Per varietal, the influence of the presence of honey bees on the number of dried caps per inflorescence was evaluated using $t$ tests.

\subsection{Does cap removal of flowers lead to higher pollen rewards?}

To investigate the significance of bees searching for flowers with loose caps, we assessed the pollen content of three types of grape flowers from the variety Grenache in the two vineyards.

(a) 'Cap on' Flowers with a partially abscised calyptra that was still covering the anthers.

(b) 'Removed' Flowers as in (a) from which we manually removed the partially abscised calyptra prior to collection. Removal was done using forceps to first pick the flower and gently squeeze the calyptra. If this resulted in complete abscission, the calyptra was subsequently carefully lifted off the flower, which was then moved into a vial.

(c) 'Cap off' Flowers that had recently lost their calyptra. These were recognised by the light colour of the anthers and the fact that the anthers had not as yet stretched to their final star shape.

Ten flowers of each type were collected in a single $1.5-\mathrm{mL}$ vial ( $n=10$ replicates per vineyard) containing $1 \mathrm{~mL}$ of water with a drop of polyoxyethylene (20) sorbitan monolaurate per $500 \mathrm{~mL}$. The vials were vortexed for $10 \mathrm{~s}$ to loosen the pollen kernels from the anthers. The pollen kernels were counted in two aliquots per sample using standard haematocytometric techniques. Analysis of variance was used to compare the pollen counts of each type of flower. The data were analysed using a univariate ANOVA, followed by post hoc comparisons using Games-Howell tests.

All statistical analyses were done in SPSS (IBM Corp 2011).

\section{RESULTS}

\subsection{Honey bees remove caps from grapevine flowers}

Behavioural observations showed that honey bees remove caps from grapevine flowers (Figure 1). Not only were calyptrae seen to open as a result of the movement of the bees on the inflorescences, the bees were also observed pulling on partially opened calyptrae, which could result in cap removal (Hogendoorn pers. obs.).

Caps fell significantly more often within $10 \mathrm{~s}$ after a bee started foraging on an inflorescence, than in $10 \mathrm{~s}$ within the 3 min preceding the arrival of the bee (Wilcoxon's matched-pairs signedranks test, $z=4.34, P<0.0005$; Figure $2 \mathrm{a}$ ). In some cases, these caps had been hanging lose in the bunch ('bunch trash'), in other cases they came off the flowers (Figure 1). 


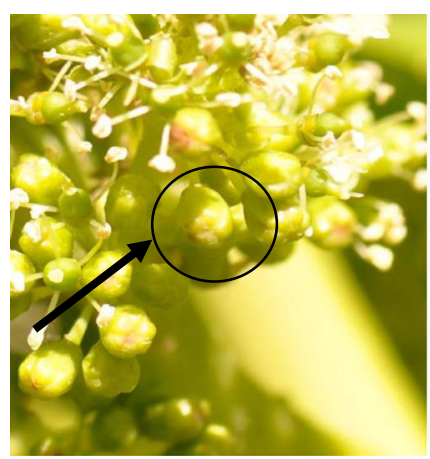

a

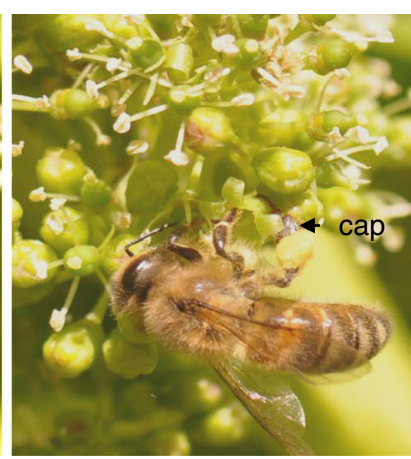

b

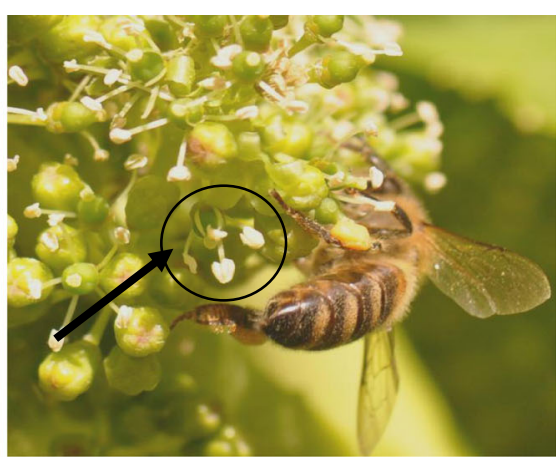

C

Figure 1. A photographic sequence showing the removal of the calyptra from a grape flower (Grenache) by a honey bee worker. a Flower with the calyptra attached. b The cap has been removed. $\mathbf{c}$ The newly opened flower is visible.

In the cages, the number of flowers covered by dried calyptrae was significantly higher in the exclusion cage than in the bee cages with Merlot $(t=7.55$, $P<0.0005$, d.f. $=36)$ and Cabernet Sauvignon $(t=$ 5.13, $P<0.0005$, d.f. $=40)$. For Chardonnay, this was not found $(t=0.41 ; P=0.69$, d.f. $=35$; Figure $2 b)$.

\subsection{Cap removal leads to higher pollen rewards}

There was a significant difference in pollen yield between flowers that had loose caps, those that had their caps manually removed and those that had just lost their caps naturally in both vineyards (ANOVA: Alverstoke: $F(2,27)=7.61, P=0.002$; Coombe: $F(2,32)=14.27, P<0.001$; Figure 3). Flowers with a partially abscised calyptra contained significantly more pollen grains than flowers that had recently dropped their caps (Games-Howell test: Alverstoke: $P=0.006$; Coombe: $P=0.001)$.

While manual removal of the calyptra resulted in some loss of pollen, the difference with flowers covered by a partially abscised calyptra was not significant (Games-Howell test: Alverstoke: $P=0.17$; Coombe: $P=0.20$ ). Manually uncapped flowers contained significantly more pollen than flowers that had recently lost their caps (Games-Howell test: Alverstoke: $P=0.02$; Coombe: $P=0.001$ ).

Assuming that uncapping by hand and by bees lead to similar pollen losses, we would predict that bees harvest $72 \%$ more pollen through cap removal than by visiting recently uncapped flowers.
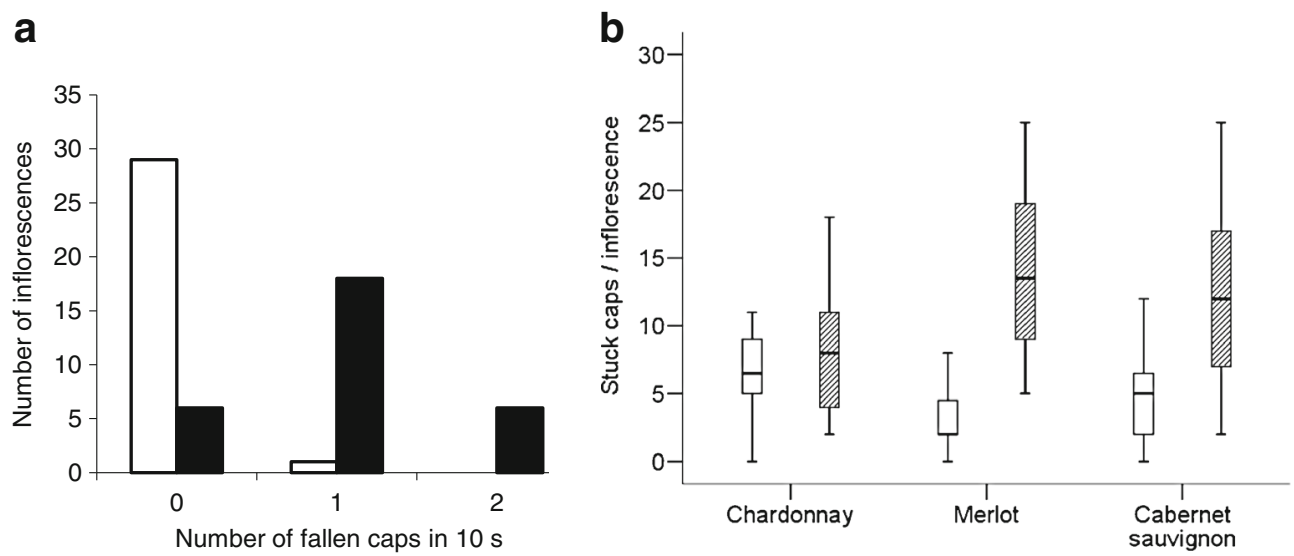

Figure 2. a The number of caps that fell from flowering inflorescences during a period of $10 \mathrm{~s}$ within 3 min before (white bars), and directly after a honey bee landed (black bars). b Box plot of the number of ovaries covered with dried calyptrae per inflorescence at the end of flowering in cages that included (white) and excluded (hatched) honey bees. 

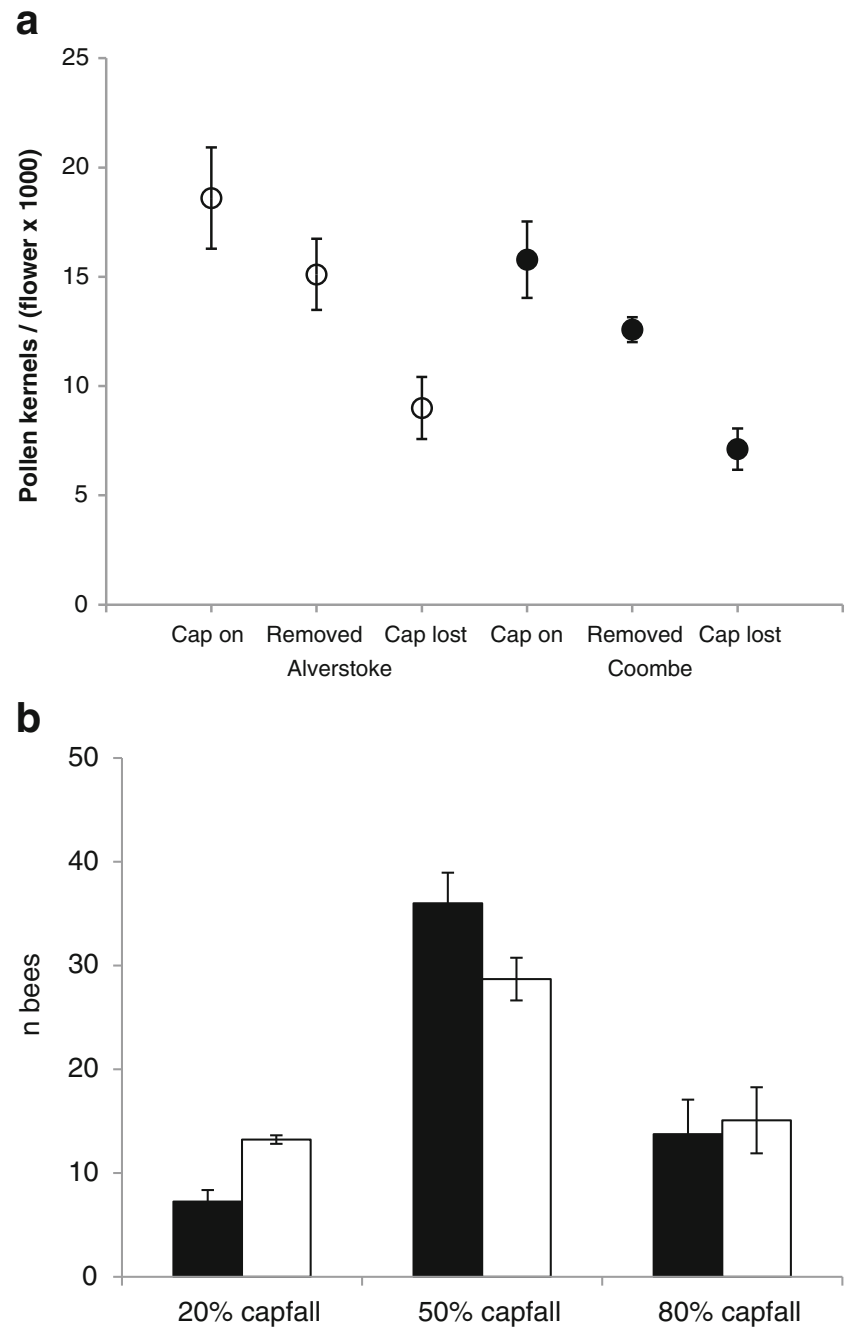

Figure 3. a The number of pollen grains per flower $(x 1000, \pm$ s.e. $)$ in Grenache when the partly abscised calyptra was present (Cap on), when the abscised calyptra was removed manually (Removed), or soon after natural capfall (Cap lost). Open dots Alverstoke vineyard, closed dots Coombe vineyard. b Average observed (black bars) and expected (white bars) number of visits by honeybees to inflorescences at different stages of flowering

\subsection{Bees preferentially visit inflorescences with high capfall}

Bees actively distinguish between flowering stages of inflorescences while foraging (Fisher's combined probability test $\chi^{2}=24.91, P=0.0006$; Figure 3). Averaging over the four observational days, the inflorescences with $20 \%$ open flowers received less visits than expected while the inflorescences with $50 \%$ open flowers received more visits than expected on the basis of the numbers present.
The inflorescences with $80 \%$ open flowers received the expected number of visits.

\section{DISCUSSION}

Using a combination of behavioural observation and experimental manipulation, we have demonstrated that honey bees remove caps from grapevine flowers, which can lead to a higher pollen yield, and that, depending on the variety, 
this can reduce the number of caps that stuck to the developing ovaries.

This is the first time cap removal has been demonstrated as a foraging strategy for honey bees. Other bee species have been observed to remove the operculum form Eucalyptus flowers (Houston 2000), but these observations do not automatically lead to the prediction that honey bees behave in the same way. This is because foraging strategies differ between bee species. For example, the use of vibration to collect pollen from buzz pollinated plants (Thorp 2000) and nectar robbing (Maloof and Inouye 2000), have been observed in numerous bee species, but have never been recorded for honey bees. So far, removal of caps from grapevine flowers has not been described for any other bee species.

During the visits of honey bees to grapevine inflorescences, caps fell at a significantly higher rate than at other times. Some of these falling caps would have been hanging in the bunch ('bunch trash'). However, our experimental finding that honey bee presence reduced the number of stuck-on caps in Merlot and Cabernet Sauvignon demonstrates that at least a proportion of the calyptrae were removed directly off the flowers.

While cap removal by honey bees was demonstrated for Merlot and Cabernet Sauvignon, it was not shown for Chardonnay. This result may be a consequence of our experimental set up: If dried caps are shed during berry growth, we may have been too late to assess effects as, at the time of our experiment, flowering was more advanced in this variety. Alternatively, the Chardonnay flowers may not have been attractive to bees, or the caps may have been on either too tight or too loose for the bees to have an effect on cap removal. Ad hoc observations of all varieties in the vineyard indicated large differences in the number of bees visiting the different flowering varieties (Hogendoorn pers. obs.), but the reasons for this variation visitation are not as yet understood.

It is likely that, by removing caps, the bees increase their pollen yield compared to collection of pollen from flowers that had recently dropped their caps. This is supported by our evidence that manual removal of lose caps lead to a $72 \%$ increase in pollen yield compared to collecting pollen from recently opened flowers. However, the benefit of manual cap removal may not accurately reflect that of cap removal by the bees, as different factors could further influence the pollen yield. For example, bees may be more efficient than humans at capturing the pollen that is released during cap removal as both the hairs on the bee's body and differences in electric loading between the pollen and the bee will enhance pollen capture (Corbet et al. 1982). In conjunction with this, the air movement produced by the wing beat and body movement of the bee on the inflorescence could cause a reduction of the amount of pollen loss in recently opened flowers. On the other hand, the movement of the bee during uncapping may cause more pollen to be distributed by the wind than our careful manual cap removal. Thus, while the existence of benefits for cap removal in terms of pollen collecting rate seems likely, this remains to be quantified and such quantification will require incorporation of search and handling times.

The bees preferentially visited the more rewarding inflorescences, i.e. inflorescences with high rates of capfall, but how did they recognise them? Visual recognition seems unlikely, as flowers of grapevine are small and green which makes them visually unattractive to bees, and they are often situated under foliage, where it is relatively dark. Because the bees distinguished between more and less rewarding inflorescences without landing, it seems likely that they identified the stage of the inflorescences using volatiles. Grapevine does not produce nectar, but there are several other possible sources of volatiles. Firstly, it has been suggested that stigmatic exudate, only present in recently uncapped flowers, is attractive for bees (Vasconcelos et al. 2009). Secondly, the pollen itself produces volatiles that are attractive to insects (Martin et al. 2009). Thirdly, it is possible that the bees specifically recognised the grape flowers with loose caps, for example on the basis of sesquiterpenes, that are released under the cap in the period just before capfall (Martin et al. 2009) and would be discharged when the cap first opens under pressure. Sesquiterpenes play multiple ecological roles, e.g. in chemical communication in bees (Leonhardt 2010), in defence against pathogens and in pollinator attraction (Huang et al. 2012). The ability of bees to directly detect grape flowers with loose caps and 
the possible role of volatiles in this recognition need to be verified.

While pollination by bees is unimportant in nearly all grape varieties (Free 1993; Vasconcelos et al. 2009), the removal of caps by honey bees could be important in several ways. For example, caps that fall from the flowers but are retained in the bunches can be sources of Botrytis infections later in the growing season (Nair et al. 1988). In addition, cap removal by honey bees could be important for varieties where persistence of the calyptra has consequences for fertilisation and consequent development of the fruit. One such variety is Pinot Noir, where the occurrence of millerandage has been associated with failure of caps to fall (Friend et al. 2003), and persistence of the calyptra causes the formation of live green ovaries (Heazlewood and Wilson 2004). Other varieties that potentially suffer from this phenomenon are Merlot and Shiraz. However, in these varieties, the importance of cap retention for the development of millerandage has not as yet been established.

Apart from a possibility to deploy honey bees for the reduction of millerandage, bees could also be used for targeted delivery of biological control agents for control of Botrytis bunch rot. This disease, caused by the fungus Botrytis cinerea, is responsible for significant economic damage in vineyards worldwide (Elmer and Michailides 2007; La Guerche et al. 2006). The pathogen enters the floral tissue, either through the cap scar or through the style and then remains latent, resuming pathogenic development as the fruit ripens (e.g. Holz et al. 2003). To prevent latent infection, two or three fungicidal sprays against $B$. cinerea are recommended during flowering. However, due to both the growing incidence of resistance against synthetic fungicides and concerns for environmental health, the industry is moving increasingly towards the use of biological control agents (Elmer and Reglinski 2006). A beneficial Trichoderma species, Trichoderma koningii, is currently marketed in Australia for the control of latent infection of Botrytis bunch rot in grapevine (Metcalf 2012). The foraging preferences of the honey bees would place them at the right location and time to deliver biological control agents for control of Botrytis bunch rot through entomovectoring
(Mommaerts and Smagghe 2011). Trials for this application are currently under way.

\section{ACKNOWLEDGMENTS}

We thank Eileen Scott, Benjamin Pike, Tiffany Barlow and Remko and Peter Leijs for help and advice and Danny le Feuvre (Australian Bee Services) for the provision of hives, and an anonymous reviewer for helpful comments and suggestions. This work was supported by grants from The University of Adelaide's Wine2030 Research Network and the Waite Research Institute.

\section{L'enlèvement du capuchon floral des fleurs de vigne par les abeilles leur permet une récolte de pollen plus importante}

Apis mellifera / Vitis vinifera / comportement
d'approvisionnement / calyptra

Die Entdeckelung von Traubenblüten durch Honigbienen führt zu erhöhter Pollenbelohnung

\section{Apis mellifera / Vitis vinifera / Sammelverhalten / Calyptra}

\section{REFERENCES}

Bolmgren, K., Eriksson, O., Linder, H.P. (2003) Contrasting flowering phenology and species richness in abiotically and biotically pollinated angiosperms. Evolution 57, 2001-2011

Charnov, E.L. (1976) Optimal foraging, the marginal value theorem. Theor. Popul. Biol. 9, 129-136

Corbet, S.A., Beament, J., Eisikowitch, D. (1982) Are electrostatic forces involved in pollen transfer? Plant Cell Environ. 5, 125-129

Elmer, P.A.G., Reglinski, T. (2006) Biosuppression of Botrytis cinerea in grapes. Plant Pathology 55, 155-177

Elmer, P.G., Michailides, T. (2007) Epidemiology of Botrytis cinerea in orchard and vine crops. In: Elad, Y., Williamson, B., Tudzynski, P., Delen, N. (eds.) Botrytis: biology, pp. 243-272. Pathology and Control, Springer Netherlands

Faegri, K., van der Pijl, L. (1971) The principles of pollination ecology. Pergamon press, Oxford

Free, J.B. (1993) Insect pollination of crops, 2nd edn. Academic, London

Friend, A.P., Creasy, G.L., Trought, M.C.T., Lang, A. (2003) Use of tagging to trace capfall and development of individual Vitis vinifera L. cv. Pinot noir flowers. Am. J. Enol. Vitic. 54, 313-317 
Goulson, D. (1999) Foraging strategies of insects for gathering nectar and pollen, and implications for plant ecology and evolution. Perspect. Plant Ecol. Evol. Syst. 2, 185-209

Hargreaves, A.L., Harder, L.D., Johnson, S.D. (2009) Consumptive emasculation: the ecological and evolutionary consequences of pollen theft. Biol. Rev. 84, 259-276

Heazlewood, J.E., Wilson, S. (2004) Anthesis, pollination and fruitset in Pinot Noir. Vitis 43, 65-68

Holz, G., Gutschow, M., Coertze, S., Calitz F.J. (2003) Occurrence of Botrytis cinerea and subsequent disease expression at different positions on leaves and bunches of grape. Plant Dis. 87, 351-358

Houston, T.F. (2000) Native bees on wildflowers in Western Australia. A synopsis of native bee visitation of wildflowers in Western Australia based on the bee collection of the Western Australian Museum. Special Publication of the Western Australian Insect Study Society Inc 2, 1-235

Huang, M., Sanchez-Moreiras, A.M., Abel, C., Sohrabi, R., Lee, S., Gershenzon, J., Tholl, D. (2012) The major volatile organic compound emitted from Arabidopsis thaliana flowers, the sesquiterpene (E)- $\beta$ caryophyllene, is a defense against a bacterial pathogen. New Phytol. 193, 997-1008

IBM Corp (2011) SPSS Statistics for Windows, 20.0 edn. IBM Corp, Armonk, NY

La Guerche, S., Dauphin, B., Pons, M., Blancard, D., Darriet, P. (2006) Characterization of some mushroom and earthy off-odors microbially induced by the development of rot on grapes. J. Agric. Food Chem. 54, 9193-9200

Leonard, A.S., Dornhaus, A., Papaj, D.R. (2011) Forgetme-not: complex floral displays, inter-signal interactions, and pollinator cognition. Curr. Zool. 57, 215224
Leonhardt, S.D., Jung, L.-M., Schmitt, T., Bluethgen, N. (2010) Terpenoids tame aggressors: role of chemicals in stingless bee communal nesting. Behav. Ecol. Sociobiol. 64, 1415-1423

Maloof, J.E., Inouye, D.W. (2000) Are nectar robbers cheaters or mutualists? Ecology 81, 2651-2661

Mangla, Y., Tandon, R. (2011) Insects facilitate wind pollination in pollen-limited Crateva adansonii (Capparaceae) Austr. J. Bot. 59, 61-69

Martin, D.M., Toub, O., Chiang, A., Lo, B.C., Ohse, S., Lund, S.T., Jr, B. (2009) The bouquet of grapevine (Vitis vinifera L. cv. Cabernet Sauvignon) flowers arises from the biosynthesis of sesquiterpene volatiles in pollen grains. Proc. Natl. Acad. Sci. 106, 72457250

Metcalf, D. (2012) A biological control system for Botrytis . Wine Vitic. J. 27, 56-58

Mommaerts, V., Smagghe, G. (2011) Entomovectoring in plant protection. Arthropod-Plant Inter. 5, 81-95

Nair, N.G., Emmett, R.W., Parker, F.E. (1988) Some factors predisposing grape berries to infection by Botrytis cinerea. N. Z. J. Exper. Agric. 16, 257-263

Pratt, C. (1971) Reproductive anatomy in cultivated grapes - review. Am. J. Enol. Vitic. 22, 92-109

Staudt, G. (1999) Opening of flowers and time of anthesis in grapevines, Vitis vinifera L. Vitis 38, 15-20

Staudt, G., Kassemeyer, H.H. (1984) Entstehen kleine Beeren bei Vitis vinifera durch Parthenocarpie? Vitis 23, 205-213

Thorp, R.W. (2000) The collection of pollen by bees. Plant Syst. Evol. 222, 211-223

Vasconcelos, M.C., Greven, M., Winefield, C.S., Trought, M.C.T., Raw, V. (2009) The flowering process of Vitis vinifera : a review. Am. J. Enol. Vitic. 60, 411-434 